\title{
Actinomycosis Hard Palate: A Rare Presentation
}

\author{
Vijeyta Dahiya ${ }^{1}$, Binu Raju George ${ }^{2}$, Kizhakkethil Ramachandran ${ }^{3}$, Shamej Peter ${ }^{4}$
}

\begin{abstract}
Actinomycosis is a gradually evolving infection caused by bacteria of genus Actinomyces. Cervicofacial involvement is the most common presentation and palatal involvement is very rare. Presented below is the case report of a 79-year-old diabetic and hypertensive female who presented with nonhealing ulcer over the hard palate for 10 months, which enlarged and formed a large oroantral fistula within 4 months. Following the diagnosis of actinomycosis by histology, complete debridement and removal of necrotic tissue was done. She was treated with intravenous crystalline penicillin 6th hourly for 4 weeks and was discharged on oral amoxicillin for 12 months with regular follow-up. Only four cases of actinomycosis hard palate have been reported in English literature so far.
\end{abstract}

Keywords: Actinomycosis, Hard palate, Oroantral fistula.

Otorhinolaryngology Clinics: An International Journal (2019): 10.5005/jp-journals-10003-1334

\section{INTRODUCTION}

Actinomycosis is a rare infection caused by saprophytes of the genus Actinomyces, which are anaerobic or microaerophilic and nonacid fast. ${ }^{1}$ The name was coined by Harz meaning the ray-like appearance of organism in the granules that characterize the lesion. Actinomycosis is a chronic granulomatous infection characterized by development of indurated swellings, mainly in connective tissue, suppuration, and discharge of "sulfur granules." ${ }^{2}$ Actinomyces israelli is the most common causative agent. In humans, it occurs in four main forms: cervicofacial, thoracic, abdominal, and pelvic. Cervicofacial mainly involves the cheek. Involvement of the hard palate is rare. Presenting below is a case report of actinomycosis involving the hard palate.

\section{Case Description}

A 79-year-old female presented with ulceration of the hard palate of 10 months' duration. For 6 months, there was nasal regurgitation and fistula at the site, which was gradually increasing in size (Fig. 1). There was no episode of bleeding from the ulcer. She was diabetic and hypertensive for 20 years on medications. She also gave history of carcinoma of breast detected $1 \frac{1}{2}$ years back treated with wide excision under general anesthesia with postoperative renal failure needing dialysis. The biopsy report came out to be an invasive papillary carcinoma. The patient has been on follow-up since then and there had been no recurrence so far. She also had history of extensive oropharyngeal and esophageal candidiasis 1 year back, which subsided with medications.

On examination of the oral cavity, there was a large $2 \times 2 \mathrm{~cm}$ ulcer with bone erosion involving anterior half of midline of the hard palate more on the right side with oroantral and oronasal communications. It was covered with slough at the edges and blackish necrotic tissue was present in the surrounding areas (Fig. 1). Dental caries was present and orodental hygiene was poor. Rest of the examination did not reveal any significant findings.

Orthopantamogram was taken, which revealed bone erosions involving the hard palate (Fig. 2). Contrast-enhanced CT paranasal sinuses (Figs 3 and 4) including maxillae and palate showed extensive bone erosion and destruction of the hard palate, inferior and inferolateral walls of both maxillary sinuses, adjacent margins
${ }^{1-4}$ Department of ENT, Government Medical College, Kozhikode,
Kerala, India

Corresponding Author: Vijeyta Dahiya, Department of ENT, Government Medical College, Kozhikode, Kerala, India, Phone: +917293206954, e-mail: dr.vijeyta@gmail.com

How to cite this article: Dahiya V, George BR, Ramachandran K, et al. Actinomycosis Hard Palate: A Rare Presentation. Int J Otorhinolaryngol Clin 2019;11(3):73-75.

Source of support: Nil

Conflict of interest: None

of upper alveolus, and anteroinferior margin of the right pterygoid bone reaching up to the left posterior ethmoid sinus and margins of sphenoid sinus.

Blood investigations were normal except for ESR, which was $50 \mathrm{~mm} /$ hour. Her blood sugar was controlled and renal parameters were normal.

Incision biopsy was taken from the lesion, which confirmed the diagnosis of actinomycosis. It showed the presence of sulfur granules with basophilic center surrounded by neutrophils (Fig. 5). Thereafter, the lesion was curetted all around with removal of

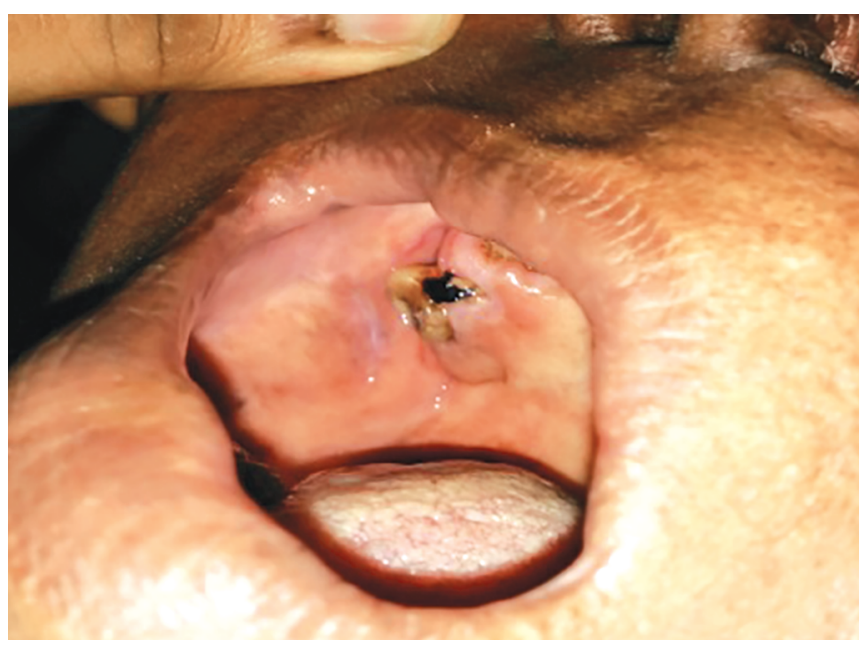

Fig. 1: Erosion of hard palate and oroantral fistula

() Jaypee Brothers Medical Publishers. 2019 Open Access This article is distributed under the terms of the Creative Commons Attribution 4.0 International License (https://creativecommons.org/licenses/by-nc/4.0/), which permits unrestricted use, distribution, and non-commercial reproduction in any medium, provided you give appropriate credit to the original author(s) and the source, provide a link to the Creative Commons license, and indicate if changes were made. The Creative Commons Public Domain Dedication waiver (http://creativecommons.org/publicdomain/zero/1.0/) applies to the data made available in this article, unless otherwise stated. 


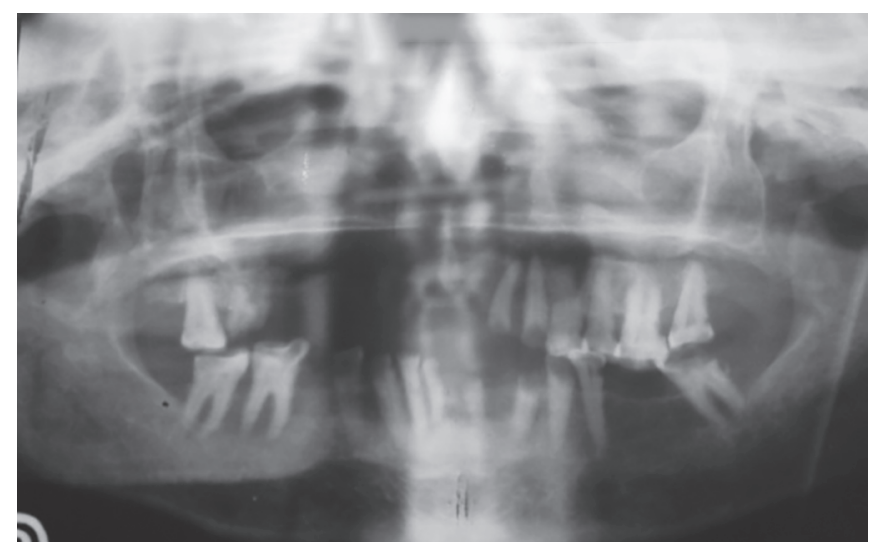

Fig. 2: Orthopantamogram

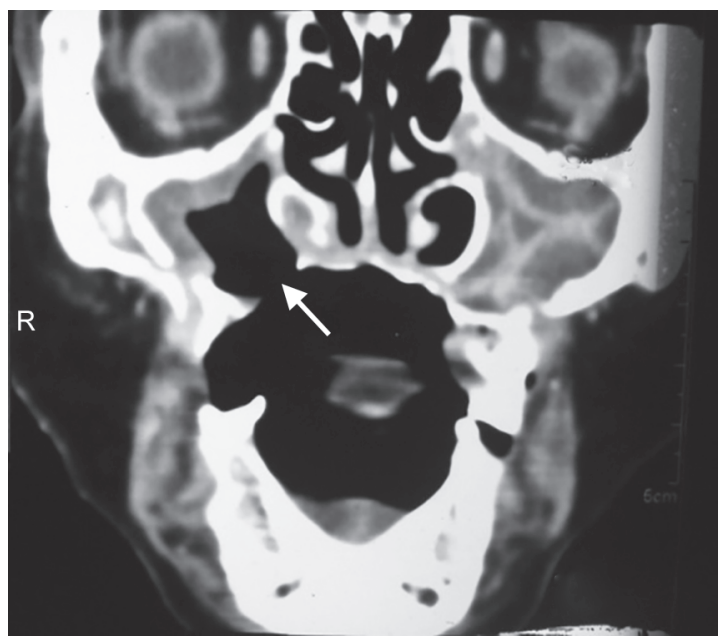

Fig. 4: CT showing oroantral fistula

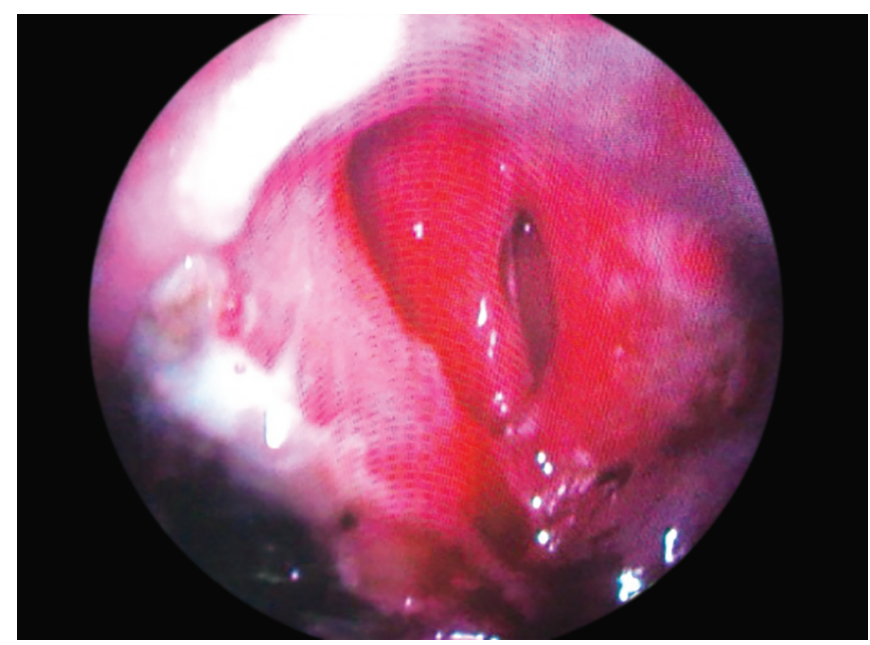

Fig. 6: Clear margins after debridement

crusts, necrotic tissues, and slough (Fig. 6). The patient was started on intravenous crystalline penicillin 6th hourly, which was continued for 4 weeks. She was discharged on oral amoxicillin 500 mg thrice daily for 12 months and was advised regular follow-up. Rehabilitation was done with dental prosthesis. She is still under follow-up and no recurrence has been detected so far.

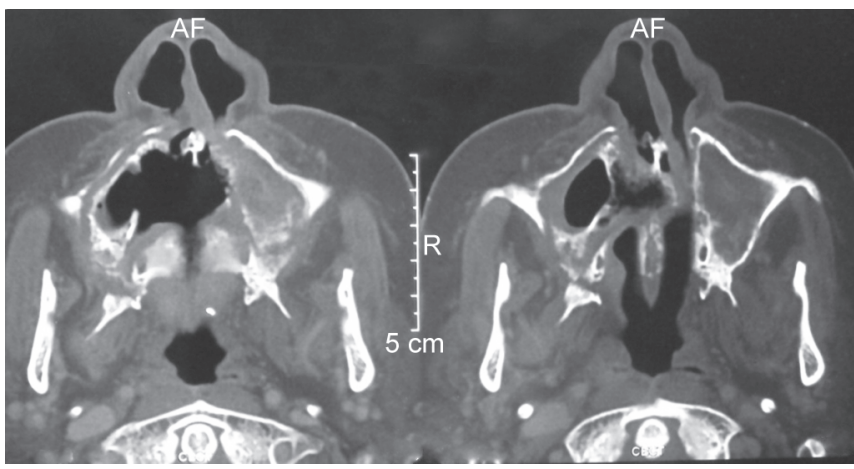

Fig. 3: CT nose and maxilla with bone erosions

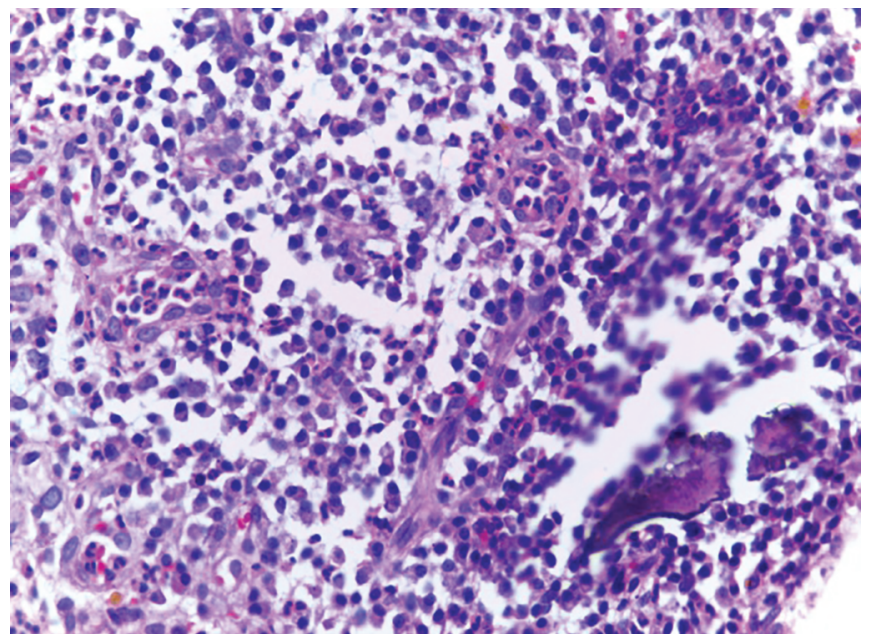

Fig. 5: Abscess with colonies of actinomycosis

\section{Review of Literature with Discussion}

Actinomycosis is a rare infection of humans caused by saprophytic bacteria. Though cervicofacial type is the most common, involvement of the hard palate is extremely rare. The mean age affected is about 30 years and the male to female ratio is $4: 1$. The mandible is more commonly involved than the maxilla. Our case is a rarity as our patient was a female of age 79 and it was the maxilla that was involved. Only four cases of actinomycosis hard palate have been reported in the English literature so far. The first case was a cocaine user who had a circular and necrotic defect in the hard palate without nasal communication on probing. ${ }^{3}$ The second case presented a necrotic ulceration along the hard palate with overhanging yellow-green slough, in addition to perilesional erythema and bogginess with reactive swelling of the upper lip. ${ }^{4} T$ The third case was characterized by a firm, infiltrative ulcerated plaque and significant tissue destruction and deformity, with an overlying yellow-white slough. ${ }^{5}$ The fourth one was a diabetic patient who presented with a painful ulcer of the hard palate. ${ }^{6}$

The bacteria spread by burrowing through the tissues and forming sinus tracts. Untreated cases can spread intracranially and lead to seizures and altered sensorium. It can also lead to osteomyelitis as a sequel, which is very resistant to treatment. So, early diagnosis and prompt treatment is needed. As the main differential diagnosis is malignancy and other granulomatous diseases like tuberculosis, nocardiosis, and fungal granuloma, ${ }^{3}$ histological confirmation is required. Histology reveals the 
sulfur granules with the classical staining pattern. Aggressive surgical debridement is needed to remove all the necrotic tissues together with long-term parenteral and oral antibiotics. The bacteria are highly sensitive to penicillins. ${ }^{5}$ Small lesions may need only oral penicillins while larger lesions with severe necrosis require intravenous penicillins followed by the oral course for about 12 months, which can be extended up to 20 months depending on the severity and clinical response on follow-up. Rehabilitation of defects can be done by appliances, splints, and tissue reconstruction. Recurrence is common and so long-term follow-up is needed.

To conclude, actinomycosis of the hard palate is a rare infection that should be kept in mind while evaluating the ulcerative lesions involving the hard palate so that this diagnosis is not missed where the mainstay of treatment is the long duration of penicillins.

\section{References}

1. Smego Jr RA, Foglia G. Actinomycosis. Clin Infect Dis 1998;26(6):12551261. DOI: 10.1086/516337.

2. Brook I. Actinomycosis: diagnosis and management. South Med J 2008;101(10):1019-1023. DOI: 10.1097/SMJ.0b013e3181864c1f.

3. Rubin MM, Krost BS. Actinomycosis presenting as midline palatal defect. J Oral Maxillofac Surg 1995;53(6):701-703. DOI: 10.1016/02782391(95)90176-0.

4. Herman WW, Whitaker SB, Williams MF. Acute actinomycosis presenting as an ulcerated palatal mass. J Oral Maxillofac Surg 1998;56(9):1098-1101. DOI: 10.1016/S0278-2391(98)90264-6.

5. De D, Dogra S, Kanwar AJ. Actinomycosis presenting as a destructive ulcerated plaque on the palate and gingiva. J Am Acad Dermatol 2011;65(6):1235-1236. DOI: 10.1016/j.jaad.2009.02.043.

6. Luiza A, Menezes M. Acute primary actinomycosis involving the hard palate of a diabetic patient. J Oral Maxillofac Surg 2014;72(3):537-541. DOI: 10.1016/j.joms.2013.08.006. 